\title{
Promoting educational, classification, treatment, and policy initiatives
}

\author{
Commentary on: Compulsive sexual behaviour disorder in the ICD-11 \\ (Kraus et al., 2018)
}

\author{
MATEUSZ GOLA ${ }^{1,2 *}$ and MARC N. POTENZA ${ }^{3,4}$ \\ ${ }^{1}$ Clinical Neuroscience Laboratory, Institute of Psychology, Polish Academy of Sciences, Warsaw, Poland \\ ${ }^{2}$ Swartz Center for Computational Neuroscience, Institute for Neural Computations, University of California San Diego, \\ San Diego, CA, USA \\ ${ }^{3}$ Departments of Psychiatry and Neurobiology, Child Study Center and CASAColumbia, Yale School of Medicine, New Haven, CT, USA \\ ${ }^{4}$ Connecticut Mental Health Center, New Haven, CT, USA
}

(Received: February 27, 2018; revised manuscript received: May 16, 2018; accepted: May 19, 2018)

\begin{abstract}
The letter by Kraus et al. (2018) published recently in World Psychiatry presents diagnostic criteria for compulsive sexual behaviors (CSBs). Here, we discuss the potential impact of including CSB disorder in ICD-11 for four areas: educational efforts related to CSB (for both clinicians and patients), investigation of underlying mechanisms and subtypes, development of personalized treatment frameworks, and answering socially important questions and advancing important prevention efforts and effective policies. Each of these four areas has their own challenges that should be addressed, and we briefly describe and discuss them. We hope that this information will help continue a dialog and provide a framework for moving forward in this area.
\end{abstract}

Keywords: compulsive sexual behavior, hypersexual disorder, sex addiction, problematic pornography use, ICD-11

In an era of unfettered Internet access on mobile devices, such behaviors as pornography use, searching for paid sexual services, and casual sexual encounters (so called hook-ups) appear to have become more prevalent. Everyday common and clinical observations indicate that for some individuals, these new forms of sexual behaviors have become problematic and prompted treatment seeking (Gola, Lewczuk, \& Skorko, 2016). Given such cases, terms such as "sex addiction" exist in the mass media and public discussion. However, despite the high social importance and interest in this phenomenon, compulsive sexual behaviors (CSBs) for years have arguably remained at the margin of systematic scientific investigation and psychiatric classification (Kafka, 2014; Kraus, Voon, \& Potenza, 2016; Potenza, Gola, Voon, Kor, \& Kraus, 2017).

Decades of scientific and clinical discussions regarding CSBs, hypersexsuality, and sex addiction have generated multiple ideas, but in comparison to other psychiatric behaviors and disorders, relatively little data exist to test them (Gola \& Potenza, 2018). On one hand, insufficient data may have hindered the inclusion of CSB disorder or related constructs [i.e., hypersexual disorder (Kafka, 2010)] in the fifth edition of Diagnostic and Statistical Manual of Mental Disorders (DSM-5; American Psychiatric Association, 2013), despite the results of a DSM-5-related field trial of hypersexual disorder (Reid et al., 2012). On the other hand, the absence of an official diagnostic entity with specified criteria may have hindered research, data collection, and educational efforts relating to CSBs. Fortunately, important recent advances in understanding significant facets of CSBs have occurred.

Kraus et al. (2018) described criteria for CSB disorder as proposed for inclusion in ICD-11. In our opinion, the World Health Organization's decision for proposing CSB disorder for inclusion in the upcoming ICD-11 is a very important step from the perspective of individuals seeking treatment for CSBs; clinicians providing such treatment; researchers interested in studying this topic; and society raising questions and receiving answers, which should ultimately inform policy efforts. We would like to briefly present perspectives on these four areas and voice most important issues that we believe are worth future investigation.

For many individuals who experience persistent patterns of difficulty or failures in controlling intense, repetitive sexual impulses or urges that result in sexual behavior associated with marked distress or impairment in personal, family, social, educational, occupational, or other important areas of functioning, it is very important to be able to name and identify their problem. It is also important that care providers (i.e., clinicians and counselors) from whom individuals may seek help are familiar with CSBs. During our

\footnotetext{
* Corresponding author: Mateusz Gola, PhD; Swartz Center for Computational Neuroscience, Institute for Neural Computations, University of California San Diego, 9500 Gilman Drive, San Diego, CA 92093 0559, USA; Phone: +1 858500 2554; Office phone: +1 858822 7543; E-mail: mgola@ucsd.edu
}

This is an open-access article distributed under the terms of the Creative Commons Attribution-NonCommercial 4.0 International License, which permits unrestricted use, distribution, and reproduction in any medium for non-commercial purposes, provided the original author and source are credited, a link to the CC License is provided, and changes - if any - are indicated. 
studies involving over 3,000 subjects seeking treatment for CSB, we have frequently heard that individuals suffering from CSB encounter multiple barriers during their seeking of help or in contact with clinicians (Dhuffar \& Griffiths, 2016). Patients report that clinicians may avoid the topic, state that such problems do not exist, or suggest that one has a high sexual drive, and should accept it instead of treating (despite that for these individuals, the CSBs may feel egodystonic and lead to multiple negative consequences). We believe that well-defined criteria for CSB disorder will promote educational efforts including development of training programs on how to assess and treat individuals with symptoms of CSB disorder. We hope that such programs will become a part of clinical training for psychologists, psychiatrists, and other providers of mental health care services, as well as other care providers including primary care providers, such as generalist physicians.

Basic questions on how best to conceptualize CSB disorder and provide effective treatments should be addressed. The current proposal of classifying CSB disorder as an impulse-control disorder is controversial as alternate models have been proposed (Kor, Fogel, Reid, \& Potenza, 2013). There are data suggesting that CSB shares many features with addictions (Kraus et al., 2016), including recent data indicating increased reactivity of reward-related brain regions in response to cues associated with erotic stimuli (Brand, Snagowski, Laier, \& Maderwald, 2016; Gola, Wordecha, Marchewka, \& Sescousse, 2016; Gola et al., 2017; Klucken, Wehrum-Osinsky, Schweckendiek, Kruse, \& Stark, 2016; Voon et al., 2014). Furthermore, preliminary data suggest that naltrexone, a medication with indications for alcohol- and opioid-use disorders, may be helpful for treating CSBs (Kraus, Meshberg-Cohen, Martino, Quinones, \& Potenza, 2015; Raymond, Grant, \& Coleman, 2010). With respect to CSB disorder's proposed classification as an impulse-control disorder, there are data suggesting that individuals seeking treatment for one form of CSB disorder, problematic pornography use, do not differ in terms of impulsivity from the general population. They are instead presented with increased anxiety (Gola, Miyakoshi, \& Sescousse, 2015; Gola et al., 2017), and pharmacological treatment targeting anxiety symptoms may be helpful in reducing some CSB symptoms (Gola \& Potenza, 2016). While it may not yet be possible to draw definitive conclusions regarding classification, more data seem to support classification as an addictive disorder when compared to an impulse-control disorder (Kraus et al., 2016), and more research is needed to examine relationships with other psychiatric conditions (Potenza et al., 2017).

Like other psychiatric conditions, CSB disorder is likely heterogeneous with multiple contributory mechanisms. The form of CSB may represent an important factor to consider with respect to disorder heterogeneity. For example, distinctions may exist relating to participating predominantly in interpersonal sexual behaviors (e.g., risky casual sex with other people or paid sexual services) versus solitary behaviors (e.g., binge pornography use and masturbation; Efrati \& Mikulincer, 2017). It is possible that the former may relate to high levels of impulsivity and sensation-seeking, and the latter may relate to high levels of anxiety, with each having different neural correlates as has been proposed for risky alcohol-use behaviors (Coleman, 1991, 2015; Gola et al., 2015; Stark \& Klucken, 2017); however, this possibility warrants direct examination.

Pharmacological and psychological treatment strategies for CSB disorder and possible subtypes should be examined. Currently, there are few systematic studies of CSB disorder, especially with consideration of potential subtypes like problematic pornography use. Such studies will need support from funding agencies (Potenza, Higuchi, \& Brand, 2018). The study of non-substance or behavioral addictions like gambling disorder does not receive governmental support the way that disorders like mood, anxiety, psychotic substance use, and most other psychiatric do (Editorial, 2018). Given individual and public health concerns related to CSBs, we hope that governmental agencies and other stakeholders (including but not limited to producers and distributors of pornography, Internet providers, and digital device manufacturers) will support research into major questions related to the prevalence of CSB disorder and its subtypes, development of culturally informed and psychometrically validated screening and assessment instruments, potential impact of Internet pornography (particularly with respect to youth exposure and developmental trajectories), and identification of vulnerability factors that may place individuals at risk for problems with CSBs. These and other questions warrant attention to improve prevention, treatment, and policy efforts in order to promote sexual health at individual and societal levels.

In our opinion, clear diagnostic criteria for CSB disorder as proposed for inclusion in ICD-11 set an important foundation for a long journey to address socially important questions. Addressing and answering such questions should provide an improved understanding of people suffering from and affected by those with CSB disorder and lead to improved sexual health for the general public.

Funding sources: This commentary was supported by the Polish National Science Centre grant for $\mathrm{MG}$ (project number: 2014/15/B/HS6/03792). Dr. MNP's involvement was supported by the National Center for Responsible Gaming Center of Excellence in Gambling Research grant. The content of the manuscript reflects the views of the authors and not necessarily the funding agencies. The funding agencies did not have input into the content of the manuscript.

Authors' contribution: Both the authors Dr. MG and Dr. MNP equally contributed to the content of the manuscript.

Conflict of interest: The authors report no financial conflict of interest with respect to the content of this manuscript. Dr. MNP has received financial support or compensation for the following: he has consulted for and advised RiverMend Health; has received research support (to Yale) from the National Institutes of Health, Mohegan Sun Casino and the National Center for Responsible Gaming; has participated in surveys, mailings, or telephone consultations related to addiction, impulse-control disorders, or other health topics; has 
consulted for gambling and legal entities on issues related to impulse control; provides clinical care in the Connecticut Department of Mental Health and Addiction Services and Problem Gambling Services Program; has performed grant reviews for the National Institutes of Health and other agencies; has edited or guest-edited journals or journal sections; has given academic lectures in grand rounds, CME events, and other clinical or scientific venues; and has generated books or book chapters for publishers of mental health texts.

\section{REFERENCES}

American Psychiatric Association. (2013). Diagnostic and statistical manual of mental disorders $\left(D S M-5^{\circledR}\right)$. Washington, DC: American Psychiatric Association.

Brand, M., Snagowski, J., Laier, C., \& Maderwald, S. (2016). Ventral striatum activity when watching preferred pornographic pictures is correlated with symptoms of Internet pornography addiction. Neuroimage, 129, 224-232. doi:10.1016/j.neuroimage. 2016.01.033

Coleman, E. (1991). Compulsive sexual behavior: New concepts and treatments. Journal of Psychology \& Human Sexuality, 4(2), 37-52. doi:10.1300/J056v04n02_04

Coleman, E. (2015). Impulsive/compulsive sexual behaviour. $A B C$ of sexual health, 259, 93.

Dhuffar, M. K., \& Griffiths, M. D. (2016). Barriers to female sex addiction treatment in the UK. Journal of Behavioral Addictions, 5(4), 562-567. doi:10.1556/2006.5.2016.072

Editorial. (2018). Science has a gambling problem. Nature, 553(7689), 379. doi:10.1038/d41586-018-01051-z

Efrati, Y., \& Mikulincer, M. (2017). Individual-based compulsive sexual behavior scale: Its development and importance in examining compulsive sexual behavior. Journal of Sex \& Marital Therapy, 44(3), 249-259. doi:10.1080/0092623X. 2017.1405297

Gola, M., Lewczuk, K., \& Skorko, M. (2016). What matters: Quantity or quality of pornography use? Psychological and behavioral factors of seeking treatment for problematic pornography use. The Journal of Sexual Medicine, 13(5), 815-824. doi:10.1016/j.jsxm.2016.02.169

Gola, M., Miyakoshi, M., \& Sescousse, G. (2015). Sex, impulsivity, and anxiety: Interplay between ventral striatum and amygdala reactivity in sexual behaviors. Journal of Neuroscience, 35(46), 15227-15229. doi:10.1523/JNEUROSCI.3273-15.2015

Gola, M., \& Potenza, M. N. (2016). Paroxetine treatment of problematic pornography use: A case series. Journal of Behavioral Addictions, 5(3), 529-532. doi:10.1556/2006.5.2016.046

Gola, M., \& Potenza, M. N. (2018). The proof of the pudding is in the tasting: Data are needed to test models and hypotheses related to compulsive sexual behaviors. Archives of Sexual Behavior, 47(5), 1323-1325. doi:10.1007/s10508018-1167-x

Gola, M., Wordecha, M., Marchewka, A., \& Sescousse, G. (2016). Visual sexual stimuli-cue or reward? A perspective for interpreting brain imaging findings on human sexual behaviors. Frontiers in Human Neuroscience, 10, 402. doi:10.3389/ fnhum.2016.00402
Gola, M., Wordecha, M., Sescousse, G., Lew-Starowicz, M., Kossowski, B., Wypych, M, Makeig, S., Potenza, M. N., \& Marchewka, A. (2017). Can pornography be addictive? An fMRI study of men seeking treatment for problematic pornography use. Neuropsychopharmacology, 42(10), 2021-2031. doi:10.1038/npp.2017.78

Kafka, M. P. (2010). Hypersexual disorder: A proposed diagnosis for DSM-V. Archives of Sexual Behavior, 39(2), 377-400. doi:10.1007/s10508-009-9574-7

Kafka, M. P. (2014). What happened to hypersexual disorder? Archives of Sexual Behavior, 43(7), 1259-1261. doi:10.1007/ s10508-014-0326-y

Klucken, T., Wehrum-Osinsky, S., Schweckendiek, J., Kruse, O., \& Stark, R. (2016). Altered appetitive conditioning and neural connectivity in subjects with compulsive sexual behavior. The Journal of Sexual Medicine, 13(4), 627-636. doi:10.1016/j. jsxm.2016.01.013

Kor, A., Fogel, Y., Reid, R. C., \& Potenza, M. N. (2013). Should hypersexual disorder be classified as an addiction? Sexual Addiction \& Compulsivity, 20(1-2), 1-15. doi:10.1080/ 10720162.2013.768132

Kraus, S. W., Krueger, R. B., Briken, P., First, M. B., Stein, D. J., Kaplan, M. S., Voon, V., Abdo, C. H. N., Grant, J. E., Atalla, E., \& Reed, G. M. (2018). Compulsive sexual behaviour disorder in the ICD-11. World Psychiatry, 17(1), 109-110. doi:10.1002/ wps.20499

Kraus, S. W., Meshberg-Cohen, S., Martino, S., Quinones, L., \& Potenza, M. (2015). Treatment of compulsive pornography use with naltrexone: A case report. The American Psychiatry Journal, 172(12), 1260-1261. doi:10.1176/appi.ajp.2015. 15060843

Kraus, S. W., Voon, V., \& Potenza, M. N. (2016). Should compulsive sexual behavior be considered an addiction? Addiction, 111(12), 2097-2106. doi:10.1111/add.13297

Potenza, M. N., Gola, M., Voon, V., Kor, A., \& Kraus, S. W. (2017). Is excessive sexual behaviour an addictive disorder? The Lancet Psychiatry, 4(9), 663-664. doi:10.1016/S22150366(17)30316-4

Potenza, M. N., Higuchi, S., \& Brand, M. (2018). Call for research into a wider range of behavioural addictions. Nature, 555, 30. doi:10.1038/d41586-018-02568-Z

Raymond, N. C., Grant, J. E., \& Coleman, E. (2010). Augmentation with naltrexone to treat compulsive sexual behavior: A case series. Annals of Clinical Psychiatry, 22(1), 56-62.

Reid, R. C., Carpenter, B. N., Hook, J. N., Garos, S., Manning, J. C., Gilliland, R., Cooper, E. B., McKittrick, H., Davtian, M., \& Fong, T. (2012). Report of findings in a DSM-5 field trial for hypersexual disorder. The Journal of Sexual Medicine, 9(11), 2868-2877. doi:10.1111/j.1743-6109.2012.02936.x

Stark, R., \& Klucken, T. (2017). Neuroscientific approaches to (online) pornography addiction. In C. Montag \& M. Reuter (Eds.), Internet Addiction (pp. 109-124). Cham, Switzerland: Springer.

Voon, V., Mole, T. B., Banca, P., Porter, L., Morris, L., Mitchell, S., Lapa, T. R., Karr, J., Harrison, N. A., Potenza, M. N., \& Irvine, M. (2014). Neural correlates of sexual cue reactivity in individuals with and without compulsive sexual behaviours. PLoS One, 9(7), e102419. doi:10.1371/journal.pone.0102419 